\title{
Conditioned Locomotion Is Not Correlated with Behavioral Sensitization to Cocaine: An Intra-Laboratory Multi-Sample Analysis
}

Gregory Hotsenpiller, Ph.D., and Marina E. Wolf, Ph.D.

Pre-clinical and clinical studies have demonstrated the importance of associative factors in regulating craving for drugs of abuse. To model these conditioned effects, we have examine cue-induced conditioned locomotion in rodents. The present study involved analysis of several of our prior studies to evaluate the relationship between conditioned locomotion and behavioral sensitization using a within-subjects analysis. Both are animal models used to study addiction, so it is important to know if one is predictive of the other, and more generally, if drug effects are predictive of conditioned effects. In all of our studies, Paired subjects received cocaine during presentation of conditioned stimuli while Unpaired subjects received saline with the stimuli and cocaine at the home cages an hour later. Paired subjects typically displayed behavioral sensitization over the course of training. After the completion of training, all subjects were tested with the conditioned stimuli in the absence of drug and conditioned locomotion was measured. The response of Unpaired subjects on the last training day was positively correlated with their response on test day, as expected since both days were nearly identical (stimuli presented without cocaine). However, for Paired subjects, the magnitude of conditioned locomotion on the drug-free test day was not positively correlated with the magnitude of behavioral sensitization. These results underscore the importance of focusing research on drug-free conditioned behaviors when attempting to model conditioned responses to drug related cues in human addicts.

[Neuropsychopharmacology 27:924-929, 2002]

(C) 2002 American College of Neuropsychopharmacology. Published by Elsevier Science Inc.
KEY WORDS: Addiction; Associative; Conditioning; Craving; Pavlovian; Sensitization

Addiction to drugs of abuse resembles the pattern of a chronic illness (McLellan et al. 2000). Much of the problem in treating drug addiction is craving, often brought on by conditioned cues, which can lead to relapse (e.g. O'Brien et al. 1998). Indeed, Foltin and Haney (2000)

From the Department of Neuroscience, FUHS/The Chicago Medical School, 3333 Green Bay Road, North Chicago, IL 60064-3095.

Address correspondence to: Dr. Marina E. Wolf, Department of Neuroscience, FUHS/The Chicago Medical School, 3333 Green Bay Road, North Chicago, IL, 60064-3095. Tel.: (847) 578-8659; Fax: (847)

578-8515; E-mail: marina.wolf@finchcms.edu

Received February 27, 2002; revised April 25, 2002; accepted May $2,2002$.

Online publication: 5/9/02 at www.acnp.org/citations/ Npp050902304. have demonstrated that humans trained in a laboratory setting to associate cocaine with novel non-drug related stimuli will exhibit conditioned craving upon presentation of the conditioned stimuli (CS+).

Because of the importance of conditioning in drug use, our laboratory has developed a rodent model of conditioned locomotion. Paired subjects receive cocaine with the conditioned stimuli while Unpaired subjects receive saline with the stimuli and cocaine at the home cages an hour later. On test day, we measure a drug free conditioned response to stimuli formerly paired with cocaine. The utility of this model is that the conditioned behavior is not goal directed, as in operant behavioral studies (Olmstead et al. 2001), and therefore is not complicated by response-reward expectancies. We have used this model to explore the neurochemical basis of drug conditioned responses (Hotsenpiller et al. 2001, 2002; Hotsenpiller and Wolf 2002). 
Of course, Pavlovian models, such as ours, do not address whether the performance of the conditioned response is associated with desire to obtain the drug. However, this seems likely based on results of place-preference studies (e.g. Bardo and Bevins 2000) and studies of cue-induced reinstatement of cocaine seeking behavior (Grimm and See 2000). Furthermore, several studies have demonstrated the ability of classically conditioned stimuli to subsequently control drug-seeking behavior following extinction of the operant response (Alleweireldt et al. 2001; Kruzich et al. 2001; Crombag and Shaham 2002). These examples indicate that classically conditioned (Pavlovian) cues can elicit drug-seeking behavior in animals.

During the course of training, Paired subjects are exposed repeatedly to cocaine and typically develop behavioral sensitization to its locomotor activating effects. Given that both conditioned locomotion and sensitization are animal models used to study the neurobiology of drug abuse, it would be valuable to determine the relationship between these two phenomena. More generally, it is important to determine whether responses to drugs themselves (e.g. sensitization) are predictive of responses to drug conditioned cues. In our initial study, which characterized a model in which cocaine was paired with discrete cues, we performed correlation analyses to assess whether the magnitude of conditioned locomotion was related to other behavioral measures during habituation sessions, training sessions (i.e. cocaine responses for paired subjects), and cocaine extinction/challenge tests (Hotsenpiller et al. 2001). Although none of the variables were significantly correlated with conditioned locomotion, a subtle relationship may have been missed given the relatively small sample size ( $\mathrm{n}=11$ rats/group). Therefore, the present multi-sample analysis of our conditioned locomotion research was conducted to further examine the relationship between sensitized behaviors and conditioned locomotion. No study to date has performed an analysis of this magnitude on the relationship between unconditioned and conditioned effects of cocaine. Furthermore, aside from our initial analysis (Hotsenpiller et al. 2001), no study has used a within-subjects analysis to investigate the relationship between unconditioned drug effects and conditioned locomotion. The importance of such an analysis is in the power derived from large sample sizes and within-subjects data, which increases the likelihood of uncovering significant associations. Furthermore, the fact that the unconditioned and conditioned responses measured are the same (ambulations) could facilitate detection of a relationship.

\section{MATERIALS AND METHODS}

\section{Subjects and Design}

Subjects were male Sprague-Dawley rats (Harlan Sprague Dawley, Indianapolis, IN, colony 205) used in our prior studies of conditioned locomotion (see Table 1 for details). All procedures were conducted in accordance with the National Institutes of Health Guide for the Care and Use of Laboratory Animals. All subjects were given a total of six cocaine injections, which were either contingent with the presentation of the stimuli (Paired, $\mathrm{n}=44$ ) or not (Unpaired, $\mathrm{n}=44$ ). In some studies (discrete cue conditioning), subjects received intervening no-stimuli days during training. See the studies cited in Table 1 for details of each conditioning regimen. The present analysis was based on 30-min cumulative ambulation counts measured during the first presentation of stimuli (Day 1 CS+), the last presentation of stimuli (Day 6 CS+), and test sessions for conditioned locomotion in the presence of the stimuli (conducted 3 to 10 days after the last presentation of stimuli). The latter test sessions provided a measure of the magnitude of conditioned locomotion for each rat. Two related but distinct measures were used to obtain an index of sensitization. The ratio of ambulations on Day $6 \mathrm{CS}+$ to those on Day 1 CS + (multiplied by 100) was used as a measure of the magnitude of sensitization that developed during training. The number of ambulations on Day 6 CS+ was used as a measure of the magnitude of the sensitized response to cocaine challenge.

Locomotor activity was measured using photobeam frames $(30 \times 50 \mathrm{~cm})$ situated around Plexiglas cages and interfaced with an analysis system (PAS, San Diego Instruments, San Diego, CA). Three pairs of photobeams were evenly spaced on the long axis of the frame. When two adjacent beams were broken in succession, this was counted as an ambulation.

\section{Data Analysis}

To test for any change in behavioral response over the course of the training sessions, independent groups $t$ tests were conducted comparing the ambulations of Paired or Unpaired subjects on Day 1 CS + to those on Day 6 CS + . $t$-tests were conducted to compare ambulation counts of Paired and Unpaired subjects during tests of conditioned locomotion. To determine if the degree of conditioned locomotion was related to behavioral sensitization, Pearson correlation coefficients were used to compare subjects' ambulations during the test for conditioned locomotion with: (1) the ratio of ambulations on Day 6 CS + to those on Day 1 CS+; and (2) the number of ambulations on Day 6 CS + .

\section{RESULTS}

\section{Training and Testing for Conditioned Locomotion}

Figure 1 (left panel) shows the ambulations for the Paired and Unpaired subjects during the first (Day 1 $\mathrm{CS}+$ ) and last (Day $6 \mathrm{CS}+$ ) days of training. As expected, the ambulations of the Unpaired subjects (re- 
Table 1. Subject Characteristics.

\begin{tabular}{|c|c|c|c|c|c|}
\hline Data Source & Subject Description & Sample Size & $\mathrm{CS}+$ & Cocaine Dose & $\begin{array}{l}\text { \# Cocaine } \\
\text { Injections }\end{array}$ \\
\hline Hotsenpiller et al. 2001 & $\begin{array}{l}3 \text { or 10-DAY groups from } \\
\text { initial study }\end{array}$ & $\mathrm{P}(11), \mathrm{UP}(11)$ & $\begin{array}{l}\text { Flashing light and } \\
\text { metronome }\end{array}$ & $15 \mathrm{mg} / \mathrm{kg}$ & 6 \\
\hline Hotsenpiller et al. 2001 & $\begin{array}{l}\text { Vehicle groups from } \\
\text { GYKI-52466 study }\end{array}$ & $\mathrm{P}(6), \mathrm{UP}(6)$ & $\begin{array}{l}\text { Flashing light and } \\
\text { metronome }\end{array}$ & $15 \mathrm{mg} / \mathrm{kg}$ & 6 \\
\hline Hotsenpiller et al. 2002 & $\begin{array}{l}\text { LIGHT groups from discrete } \\
\text { Fos study }\end{array}$ & $\mathrm{P}(6), \mathrm{UP}(6)$ & Flashing light & $20 \mathrm{mg} / \mathrm{kg}$ & 6 \\
\hline Hotsenpiller et al. 2002 & $\begin{array}{l}\text { Groups from generalized } \\
\text { contextual cues study }\end{array}$ & $\mathrm{P}(6), \mathrm{UP}(6)$ & $\begin{array}{l}\text { Generalized } \\
\text { context }\end{array}$ & $20 \mathrm{mg} / \mathrm{kg}$ & 6 \\
\hline Hotsenpiller and Wolf 2002 & $\begin{array}{l}\text { Saline groups from } \\
\text { baclofen study }\end{array}$ & $\mathrm{P}(6), \mathrm{UP}(6)$ & $\begin{array}{l}\text { Flashing light and } \\
\text { metronome }\end{array}$ & $15 \mathrm{mg} / \mathrm{kg}$ & 6 \\
\hline Pilot studies (unpublished) & $\begin{array}{l}\text { Groups from discrete } \\
\text { cue studies }\end{array}$ & $\mathrm{P}(9), \mathrm{UP}(9)$ & Flashing light & $20 \mathrm{mg} / \mathrm{kg}$ & 6 \\
\hline
\end{tabular}

This table provides relevant information concerning the subjects used in the present pooled analysis. Equivalent numbers of Paired (P) and Unpaired (UP) subjects were taken from each study. All subjects received 6 training sessions with cocaine (P) or saline (UP) and the particular conditioned stimulus/stimuli (CS+).

ceiving saline during sessions) did not change. However, the Paired subjects (receiving cocaine during sessions) displayed significantly more ambulations on Day 6 CS + than on Day 1 CS $+(p<.01)$, indicating behavioral sensitization. Cocaine-free testing of subjects with the stimuli on test day revealed conditioned locomotion, that is, significantly more ambulations in the Paired group than in the Unpaired group $(p<.001)$ (Figure 1, right panel).

\section{Relationship of Conditioned Locomotion to Sensitization}

Table 2 shows the Pearson correlation coefficients obtained from comparison of ambulation counts during the test for conditioned locomotion to the magnitude of sensitization that developed during training (Day 6/Day 1 CS $+\times 100)$ and the magnitude of the sensitized response to cocaine challenge (Day $6 \mathrm{CS}+$ ). The behavior of the Unpaired subjects on the last day of training (Day
TRAINING

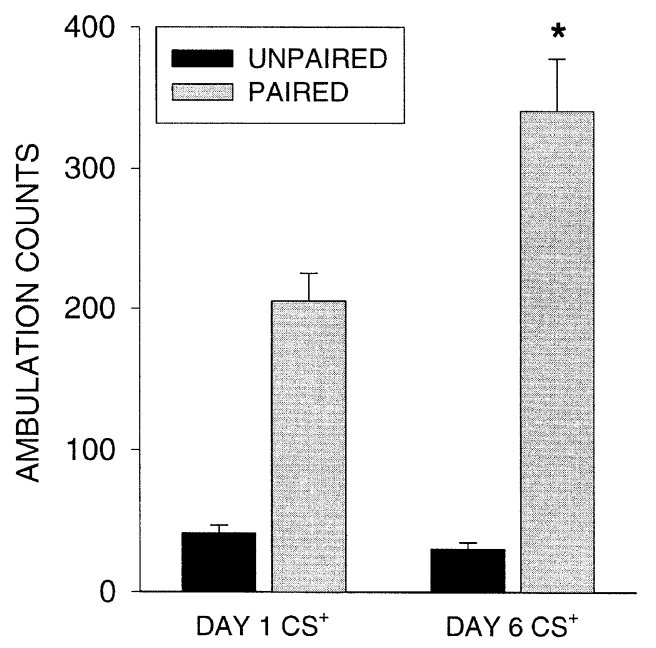

TESTING

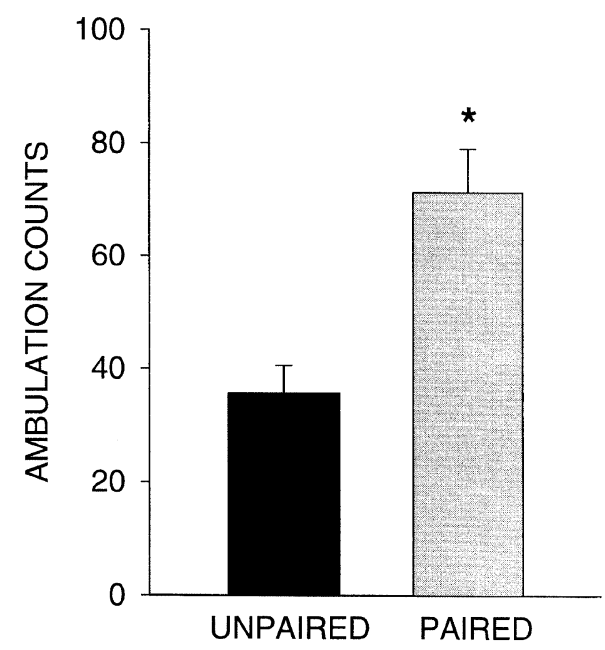

Figure 1. Behavioral patterns of Unpaired and Paired subjects during training and testing. Left panel. The behavior of the Unpaired subjects did not change from the first training session with the conditioned stimuli (Day 1 CS+) to the last (Day 6 $\mathrm{CS}+)$. In contrast, the Paired subjects displayed significantly more ambulations during Day $6 \mathrm{CS}+$ than Day $1 \mathrm{CS}+\left({ }^{*} p<\right.$ $.01)$, indicating behavioral sensitization. Right panel. During drug-free tests for conditioned locomotion, Paired subjects demonstrated increased ambulations in response to the stimuli as compared with the Unpaired subjects $\left({ }^{*} p<.001\right)$. $\mathrm{n}=44$ subjects/group. 
Table 2. Relationship of Conditioned Locomotion to Behavioral Sensitization as Assessed by Correlation Coefficients.

\begin{tabular}{lcc}
\hline & Day 6/Day 1 CS + & Day 6 CS + \\
\hline Unpaired & -0.061 & $0.807^{*}$ \\
Paired & $-0.309^{*}$ & 0.176 \\
\hline
\end{tabular}

Pearson correlation coefficients comparing locomotor scores (ambulations) from tests of conditioned locomotion for the Paired $(n=44)$ and the Unpaired ( $\mathrm{N}=44)$ subjects to: 1$)$ The ratio of ambulations from the last day of stimuli training to the first (Day 6/Day $1 \mathrm{CS}+$ ). The ratio provides a measure of the magnitude of sensitization that developed during training. 2) Ambulations on the last day of stimuli training (Day $6 \mathrm{CS}+$ ) in which Paired subjects received cocaine and Unpaired subjects received saline. This represents the magnitude of the sensitized response to cocaine challenge for the Paired subjects. ${ }^{*} p<0.05$, see text for details.

$6 \mathrm{CS}+)$ was significantly correlated with their behavior on test day ( $p<.05)$. This is not surprising, since the test session was nearly identical to the last training session (stimuli presented in the absence of cocaine). Consider- ing that the behavior of the Unpaired subjects did not change from Day $1 \mathrm{CS}+$ to Day $6 \mathrm{CS}+$, it is not surprising that no correlation was detected between the ratio of these training days and the response on test day.

The magnitude of the sensitized response for the Paired subjects (Day $6 \mathrm{CS}+$ ) was not related to their behavior during the drug-free test for conditioned locomotion. However, there was a significant negative correlation between the magnitude of sensitization that developed during training (Day 6/Day $1 \mathrm{CS}+\times 100$ ) and ambulations during the test for conditioned locomotion $(p<.05)$. Inspection of the data suggested that this effect was largely due to a minority of subjects $(\mathrm{n}=$ 5) that showed an unusually high degree of sensitization (symbols located above correlation line in Figure 2 ). These five subjects came from three separate studies and thus are not an artifact of a particular experiment. Re-analysis of the data, excluding those subjects with a degree of sensitization greater than twice the mean, showed an absence of correlation (Figure 2, inset). Therefore, overall, the magnitude of behavioral sensiti-

\section{PAIRED SUBJECTS}

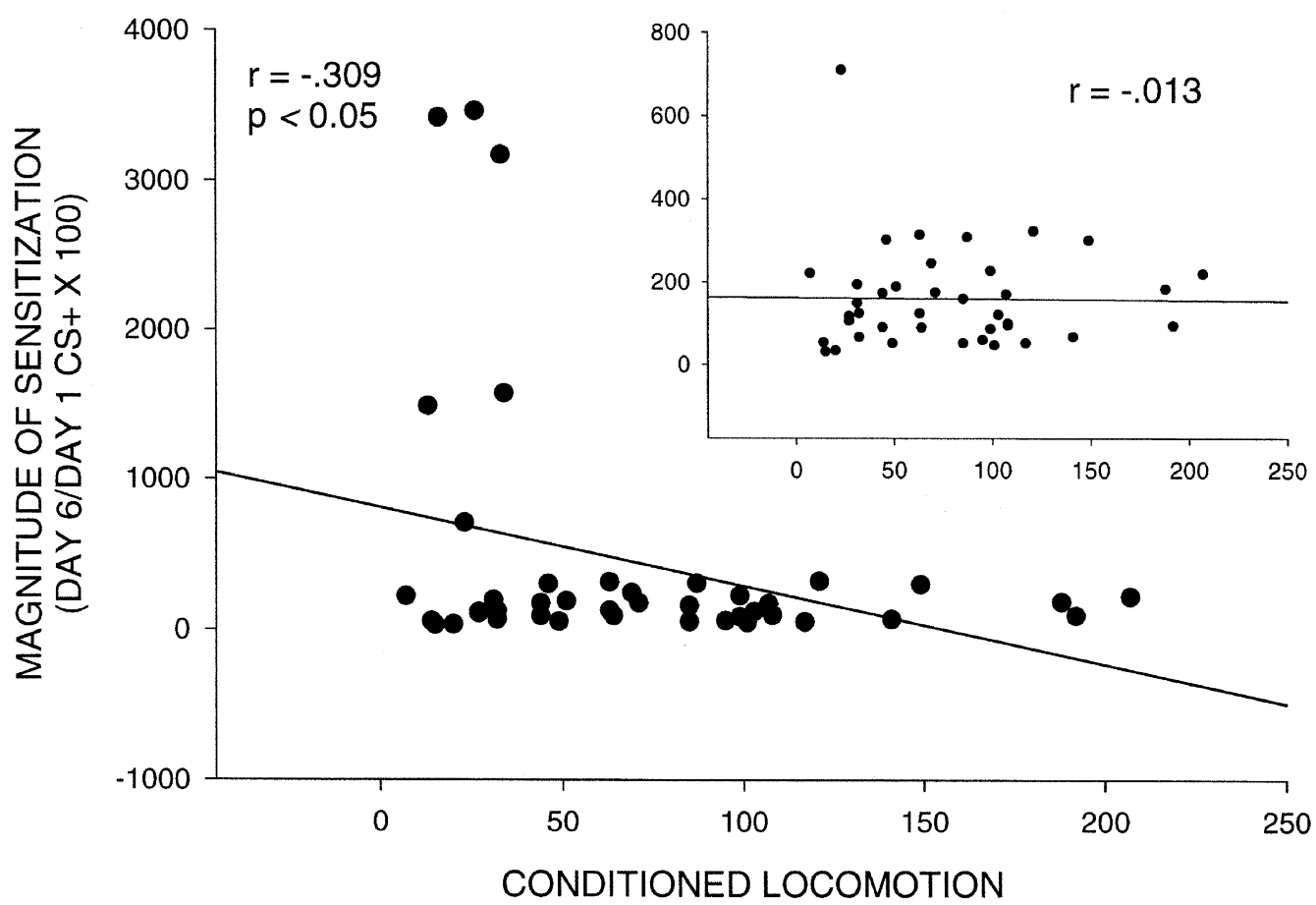

Figure 2. Lack of correlation between conditioned locomotion on test day and the magnitude of behavioral sensitization that developed during training in Paired subjects. Main diagram. When all Paired subjects were included in the correlation analysis $(n=44)$, there was a significant negative correlation between conditioned locomotion and the magnitude of sensitization that developed during training (Day 6/Day 1 CS $+\times 100$ ). However, this effect was attributable to a minority of subjects displaying an unusually high degree of sensitization. Inset. When data were re-analyzed, excluding those subjects exhibiting a degree of sensitization greater then twice the mean $(n=5)$, the negative correlation was no longer evident. 
zation to cocaine in the Paired rats is not related to their conditioned locomotion during test sessions.

\section{DISCUSSION}

Previous studies have used locomotion as a measure of motivational drive (e.g. Wagner 1959). In fact, rats have difficulty learning to run slower for reward and often must develop idiosyncratic patterns of behavior to reduce overall speed (Rashotte and Amsel 1968; Amsel and Rashotte 1969). Using distance and time schedules, Williams (1966) showed that rats increase their running speed not in an attempt to reduce the delay of reward but rather in proportion to the degree of reward expected based on previous trials. This phenomenon has been replicated with various types of rewards. For example, rats will run faster down an alley to reach a chamber in proportion to the degree that the chamber is associated with prior exposure to rewarding electrical brain stimulation (Gallistel et al. 1974) or to the reinforcing effects of heroin (McFarland and Ettenberg 1995).

Considering the above, it may seem surprising that the degree of psychostimulant-induced conditioned locomotion is not related to the magnitude of behavioral sensitization that develops in the presence of the conditioned stimuli during training, especially since prior sensitization enhances the acquisition of Pavlovian associations to appetitive conditioned stimuli (Harmer and Phillips 1999). However, other groups have also reported dissociations between conditioned and unconditioned responses to psychostimulants (Damianopoulos and Carey 1992; Martin-Iverson and Fawcett 1996; Crombag et al. 2000; Sutton et al. 2000). In a prior study involving a subset of the present subjects, we showed that even after the conditioned response was extinguished, the response of Paired subjects to cocaine challenge was unaltered; in fact, it was significantly correlated with their cocaine response during the last training session (Hotsenpiller et al. 2001). Others have also demonstrated persistence of psychostimulant sensitization after extinction of a drug-free conditioned response (Stewart and Vezina 1991; Carey and Gui 1998). Furthermore, Anagnostaras and Robinson (1996) have found that sensitized responses remain context specific following extinction of the conditioned response. These observations suggest that mechanisms underlying behavioral sensitization can be dissociated from those mediating drug-free conditioned responses. Other studies have shown that the degree of conditioned place preference to psychostimulants can be dissociated from unconditioned locomotor effects (Shimosato and Ohkuma 2000) and from self-administration behavior (Bardo et al. 1999).

These dissociations likely reflect the fact that different neural circuits are involved in cue-induced reward- seeking behavior as opposed to those regulating behaviors directly producing reward on a contingent basis (Grimm and See 2000; Vorel et al. 2001). It therefore becomes apparent that these associative responses are not a mere reflection of the unconditioned effects of psychostimulants, but rather an independent phenomenon from unconditioned (for example, sensitized) responses. Such independence of unconditioned and conditioned responses is in contrast to early theories regarding context specific behaviors involving reward. For instance, Thorndike (1911) proposed that behavior evoked by a context after training is the result of that particular behavioral "impulse" being performed during the formation of the association, and hence is intimately linked to the behavior during training.

Realistically, conditioned responses to stimuli formerly paired with psychostimulants are probably the result of numerous influences with both hedonic and aversive qualities (Wikler 1973; O'Brien et al. 1998; Hotsenpiller et al. 2001). The lack of a straightforward relationship between psychostimulant-induced responses (such as behavioral sensitization) and conditioned responses indicates that studies on the former will not necessarily be useful in explaining the neurobiological basis of behaviors guided by associative elements. This underscores the importance of examining neural mechanisms underlying conditioned responses under drugfree testing conditions. Focusing on associative responses may help to develop an understanding of the neural substrates underlying cue-induced craving. Targeting research toward understanding the neurochemistry of craving is an important and rational approach toward developing medications to prevent relapse, considering that craving has been shown to predict the likelihood that addicts will resume drug use during treatment (Hartz et al. 2001).

\section{ACKNOWLEDGMENTS}

Supported by USPHS grant DA09621 (MEW), Independent Scientist Award DA00453 (MEW), and an individual M.D./Ph.D. predoctoral fellowship DA06058 (GH).

\section{REFERENCES}

Alleweireldt AT, Weber SM, Neisewander JL (2001): Passive exposure to a contextual discriminative stimulus reinstates cocaine-seeking behavior in rats. Pharmacol Biochem Behav 69:555-560

Anagnostaras SG, Robinson TE (1996): Sensitization to the psychomotor stimulant effects of amphetamine: modulation by associative learning. Behav Neurosci 110:1397-1414

Amsel A, Rashotte ME (1969): Transfer of experimenterimposed slow response patterns to extinction of a con- 
tinuously rewarded response. J Comp Physiolog Psychol 69:185-189

Bardo MT, Bevins RA (2000): Conditioned place preference: what does it add to our preclinical understanding of drug reward? Psychopharmacology (Berl) 153:31-43

Bardo MT, Valone JM, Bevins RA (1999): Locomotion and conditioned place preference produced by acute intravenous amphetamine: role of dopamine receptors and individual differences in amphetamine self-administration. Psychopharmacology (Berl) 143:39-46

Carey RJ, Gui J (1998): Cocaine conditioning and cocaine sensitization: what is the relationship? Behav Brain Res 92:67-76

Crombag HS, Badiani A, Maren S, Robinson TE (2000): The role of contextual versus discrete drug-associated cues in promoting the induction of psychomotor sensitization to intravenous amphetamine. Behav Brain Res 116:1-22

Crombag HS, Shaham Y (2002): Renewal of drug seeking by contextual cues after prolonged extinction in rats. Behav Neurosci 116:169-173

Damianopoulos EN, Carey RJ (1992): Conditioning, habituation and behavior reorganization factors in chronic cocaine effects. Behav Brain Res 49:149-157

Foltin RW, Haney M (2000): Conditioned effects of environmental stimuli paired with smoked cocaine in humans. Psychopharmacology (Berl) 149:24-33

Gallistel CR, Stellar JR, Bubis E (1974): Parametric analysis of brain stimulation reward in the rat: I. The transient process and the memory containing process. J Comp Physiolog Psych 87:848-859

Grimm JW, See RE (2000): Dissociation of primary and secondary reward-relevant limbic nuclei in an animal model of relapse. Neuropsychopharmacology 22:473-479

Harmer CJ, Phillips GD (1999): Enhanced conditioned inhibition following repeated pretreatment with d-amphetamine. Psychopharmacology (Berl) 142:120-131

Hartz DT, Frederick-Osborne SL, Galloway GP (2001): Craving predicts use during treatment for methamphetamine dependence: a prospective, repeated-measures, within-subject analysis. Drug Alcohol Depend 63:269-276

Hotsenpiller G, Giorgetti M, Wolf ME (2001): Alterations in behavior and glutamate transmission following presentation of stimuli previously associated with cocaine exposure. Eur J Neurosci 14:1843-1855

Hotsenpiller G, Horak BT, Wolf ME (2002): Dissociation of conditioned locomotion and Fos induction in response to stimuli formerly paired with cocaine. Behav Neurosci 116:634-645

Hotsenpiller G, Wolf ME (2002): Baclofen attenuates condi- tioned locomotion to cues associated with cocaine administration and stabilizes extracellular glutamate levels in rat nucleus accumbens. (submitted)

Kruzich PJ, Congleton KM, See RE (2001): Conditioned reinstatement of drug-seeking behavior with a discrete compound stimulus classically conditioned with intravenous cocaine. Behav Neurosci 115:1086-1092

Martin-Iverson MT, Fawcett SL (1996): Pavlovian conditioning of psychomotor stimulant-induced behaviors: has convenience led us astray? Behav Pharmacol 7:24-41

McFarland K, Ettenberg A (1995): Haloperidol differentially affects reinforcement and motivational processes in rats running an alley for intravenous heroin. Psychopharmacology (Berl) 122:346-350

McLellan AT, Lewis DC, O'Brien CP, Kleber HD (2000): Drug dependence, a chronic medical illness. JAMA 284:1689-1695

O'Brien CP, Childress AR, Ehrman R, Robbins SJ (1998): Conditioning factors in drug abuse: can they explain compulsion? J Psychopharm 12:15-22

Olmstead MC, Lafond MV, Everitt BJ, Dickinson A (2001): Cocaine seeking by rats is a goal-directed action. Behav Neurosci 115:394-402

Rashotte ME, Amsel A (1968): Transfer of slow-response rituals to extinction of a continuously rewarded response. J Comp Physiolog Psych 66:432-443

Shimosato K, Ohkuma S (2000): Simultaneous monitoring of conditioned place preference and locomotor sensitization following repeated administration of cocaine and methamphetamine. Pharmacol Biochem Behav 66:285-292

Stewart J, Vezina P (1991): Extinction procedures abolish conditioned stimulus control but spare sensitized responding to amphetamine. Behav Pharmacol 2:65-71

Sutton MA, Karanian DA, Self DW (2000): Factors that determine a propensity for cocaine-seeking behavior during abstinence in rats. Neuropsychopharmacology 22:626-641

Thorndike EL (1911): Animal Intelligence. New York, The Macmillan Company

Vorel SR, Liu X, Hayes RJ, Spector JA, Gardner EL (2001): Relapse to cocaine-seeking after hippocampal theta burst stimulation. Science 292:1175-1178

Wagner AR (1959): The role of reinforcement and nonreinforcement in an "apparent frustration effect." J Exper Psych 57:130-136

Wikler A (1973): Dynamics of drug dependence: Implications of a conditioning theory for research and treatment. Arch Gen Psychiatry 28:611-616

Williams DR (1966): Relation between response amplitude and reinforcement. J Exper Psych 71:634-641 